\title{
Ravitch versus Nuss procedure for pectus excavatum: systematic review and meta-analysis
}

\author{
Aran Kanagaratnam, Steven Phan, Vakhtang Tchantchaleishvilli, Kevin Phan \\ Collaborative Research (CORE) Group, Macquarie University, Sydney, Australia \\ Correspondence to: Kevin Phan. Collaborative Research (CORE) Group, Macquarie University, Sydney, Australia; University of Sydney, Sydney, \\ Australia; University of New South Wales, Sydney, Australia. Email: kphan.vc@gmail.com.
}

\begin{abstract}
Background: Pectus excavatum is the most common congenital chest wall deformity. The two most common surgical techniques for its correction are the modified Ravitch technique and the minimally invasive Nuss technique. Despite both procedures being used widely, data comparing them are scarce.

Methods: We conducted a systematic review and meta-analysis of comparative studies to evaluate these procedures. A systematic search of the literature was performed from six electronic databases. Pooled metaanalysis was conducted using odds ratio (OR) and weighted mean difference (WMD).

Results: A total of 13 studies comprising 1,432 pediatric (79.3\%) and adult (20.7\%) patients were identified, including 912 patients undergoing the Nuss procedure compared to 520 patients undergoing the Ravitch procedure. There was no significant difference found between the Nuss group versus Ravitch group in pediatric patients with regard to overall complications ( $\left.\mathrm{OR}=1.16 ; 95 \% \mathrm{CI}: 0.61-2.19 ; \mathrm{I}^{2}=56 \% ; \mathrm{P}=0.65\right)$, reoperations $\left(6.1 \%\right.$ vs. 6.4\%; OR =1.00; 95\% CI: 0.40-2.50; $\left.\mathrm{I}^{2}=0 \% ; \mathrm{P}=1.00\right)$, wound infections $(\mathrm{OR}=0.58$; 95\% CI: $0.23-1.46 ; \mathrm{I}^{2}=0 \% ; \mathrm{P}=0.25$ ), hemothorax (1.6\% vs. $1.3 \%$; OR =0.74; $95 \%$ CI: $0.21-2.65 ; \mathrm{I}^{2}=12 \%$; $\mathrm{P}=0.64)$, pneumothorax (3.4\% vs. $1.5 \%$; OR $=1.11 ; 95 \% \mathrm{CI}: 0.42-2.93 ; \mathrm{I}^{2}=0 \% ; \mathrm{P}=0.83$ ) or pneumonia $\left(\mathrm{OR}=0.15 ; 95 \% \mathrm{CI}: 0.02-1.48 ; \mathrm{I}^{2}=0 \% ; \mathrm{P}=0.10\right)$. Adult patients undergoing the Nuss procedure had a higher incidence of overall complications ( $\left.\mathrm{OR}=3.26 ; 95 \% \mathrm{CI}: 1.01-10.46 ; \mathrm{I}^{2}=0 \% ; \mathrm{P}=0.05\right)$, though there were far fewer studies that reported data.
\end{abstract}

Conclusions: These results suggest no difference between the Nuss and Ravitch procedures for pediatric patients, while in adults the Ravitch procedure resulted in fewer complications.

Keywords: Pectus excavatum; Nuss; Ravitch; minimally invasive; systematic review; meta-analysis

Submitted Jun 12, 2016. Accepted for publication Aug 11, 2016.

doi: $10.21037 /$ acs.2016.08.06

View this article at: http://dx.doi.org/10.21037/acs.2016.08.06

\section{Introduction}

Pectus excavatum is the most common congenital chest wall deformity, affecting 1 to 8 per 1,000 live births (1). Psychological symptoms resulting from body image issues are common and can severely curtail the quality of life of some individuals (2). Physiological limitations caused by this deformity, particularly cardiovascular (3) and pulmonary impairments (4), have meant that correction of pectus excavatum can play a major role in improving the physical activity and quality of life of patients. The first technique of pectus excavatum repair was proposed by Ravitch in 1949, an open technique that required partial resection of the cartilage, xiphoid excision and osteotomy of the sternum (5). Multiple modifications were proposed to this procedure in some institutions, such as placement of a metal strut to support the sternum that would be removed after 6 months to a year. It was not until nearly half a century later that an alternative surgical option was published. In 1998 Nuss proposed a minimally invasive technique, publishing his 10year experience that suggested it resulted in lower blood loss and shorter operative times (6). This technique gained popularity quickly because it avoided cartilage resection and osteotomy. 
Both procedures continue to be in use today, yet accurate comparisons between them are scarce. Given the range of post-operative complications, changes to cardiovascular and pulmonary function and recovery time, the need for these comparisons is clear. Only one systematic review and meta-analysis has been published, and this focused only on the pediatric population (7). This has made it difficult to compare patient outcomes. While pectus excavatum repair was originally intended for use in pre-pubertal children, it is now often used in adolescents and adults. Examining specific complications such as pneumothorax, hemothorax and wound infections has been difficult because of the paucity of data and its low quality. Most institutions perform pectus excavatum repair using only one of the types of technique, further making direct comparison difficult. This study aimed to compare outcomes of Nuss and Ravitch procedures, looking both at total complications as well as specific ones including bar displacement, pneumothorax, hemothorax, wound infections and pneumonia.

\section{Methods}

The present study was performed according to recommended international PRISMA guidelines and recommendations for systematic reviews and meta-analyses $(8,9)$.

\section{Literature search}

Electronic searches were performed using Ovid Medline, PubMed, Cochrane Central Register of Controlled Trials (CCTR), Cochrane Database of Systematic Reviews (CDSR), ACP Journal Club and Database of Abstracts of Review of Effectiveness (DARE) from their dates of inception to March 2016. To achieve maximum sensitivity of the search strategy and identify all studies, we combined the terms: "pectus excavatum" AND ("Nuss" OR "Ravitch" OR "minimally invasive") AND ("pediatric" OR "adult") as either keywords or MeSH terms. The reference lists of all retrieved articles were reviewed for further identification of potentially relevant studies. All identified articles were systematically assessed using the inclusion and exclusion criteria.

\section{Selection criteria}

Eligible studies for the present systematic review and metaanalysis included comparative studies in which patient cohorts underwent either a minimally invasive Nuss procedure or open Ravitch procedure for pectus excavatum surgery. All pediatric, adult and mixed cohort studies were included for the present review. When institutions published duplicate studies with accumulating numbers of patients or increased lengths of follow-up, only the most complete reports were included for quantitative assessment at each time interval. All publications were limited to those involving human subjects and in the English language. Abstracts, case reports, conference presentations, editorials and expert opinions were excluded. Review articles were omitted because of potential publication bias and duplication of results.

\section{Data extraction}

All data were extracted from article texts, tables and figures. Two investigators independently reviewed each retrieved article (K.P. and A.K.). Discrepancies between the two reviewers were resolved by discussion and consensus. Assessment of risk of bias for each selected study was performed according to the most updated Cochrane statement. Discrepancies between the two reviewers were resolved by discussion and consensus.

\section{Statistics}

The odds ratio (OR) or weighted mean difference (WMD) was used as a summary statistic. In the present study, both fixed- and random-effect models were tested. In the fixedeffects model, it was assumed that treatment effect in each study was the same, whereas in a random-effects model, it was assumed that there were variations between studies. $\chi^{2}$ tests were used to study heterogeneity between trials. The $\mathrm{I}^{2}$ statistic was used to estimate the percentage of total variation across studies, owing to heterogeneity rather than chance, with values greater than $50 \%$ considered as substantial heterogeneity. $I^{2}$ can be calculated as: $I^{2}=100 \% \times$ $(\mathrm{Q}-\mathrm{df}) / \mathrm{Q}$, with $\mathrm{Q}$ defined as Cochrane's heterogeneity statistics and $\mathrm{df}$ defined as degree of freedom. If there was substantial heterogeneity, the possible clinical and methodological reasons for this were explored qualitatively. In the present meta-analysis, the results using the randomeffects model were presented to take into account the possible clinical diversity and methodological variation between studies. Specific analyses considering confounding factors were not possible because raw data were not available. All $\mathrm{P}$ values were 2-sided. All statistical analysis was conducted with Review Manager Version 5.3.3 


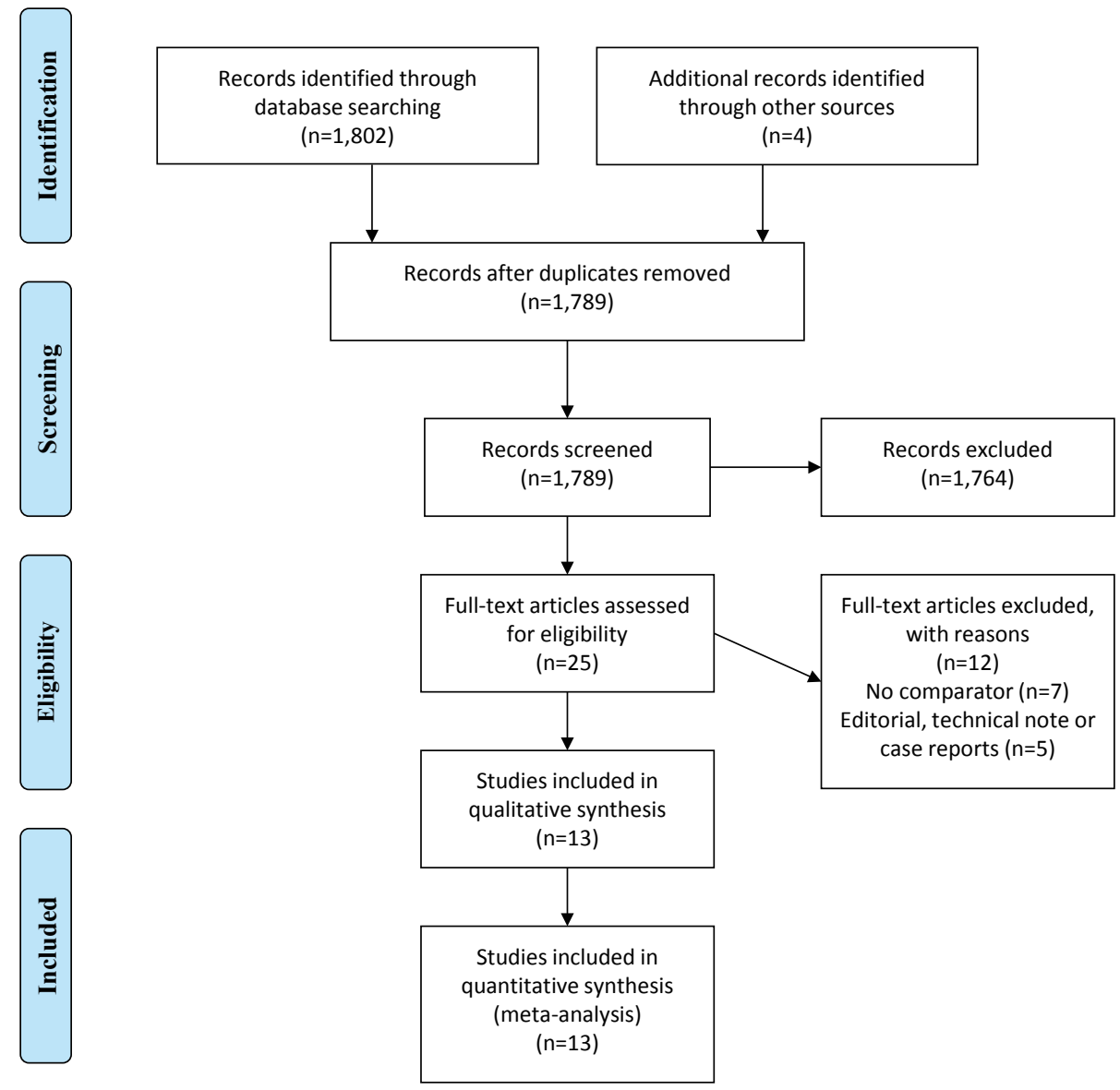

Figure 1 PRISMA chart demonstrating the search strategy for the presenting systematic review comparing Nuss versus Ravitch procedures for pectus excavatum.

(Cochrane Collaboration, Software Update, Oxford, UK).

\section{Results}

\section{Literature search}

A total of 1,802 references were identified through electronic database searches. After exclusion of duplicate or irrelevant references, 1,789 potentially relevant articles were retrieved. After detailed evaluation of these articles, 25 articles remained for assessment. Manual search of reference lists did not yield any new studies. After applying the selection criteria, 13 comparative studies $(6,10-21)$ were finally included for analysis, including 10 studies with pediatric population, two studies on adult patients $(20,21)$, and one study (19) with a mixed pediatric and adult population (Figure 1). Studies with adult patients were required to have an average age of 20 or greater; however, as this was a mean, these studies still likely reported some pediatric cases. There were a total of 1,432 patients, including 912 patients undergoing the Nuss procedure compared to 520 patients undergoing the Ravitch procedure. Study characteristics and baseline traits are summarized in Table 1.

\section{Baseline and operative parameters}

There was no significant difference between the Nuss and Ravitch groups in terms of mean baseline age (WMD -0.71; $\mathrm{P}=0.50$ ). The groups were also comparable in terms of proportion of males $(72.9 \%$ vs. $57.8 \% ; \mathrm{P}=0.71)$, weight $(\mathrm{P}=0.50)$, asthma $(\mathrm{P}=0.52)$ and $\mathrm{CT}$ chest index $(\mathrm{P}=0.32)$. Operation duration was significantly shorter for the Nuss procedure (WMD -67.5 minutes, 95\% CI: -125.5 to -9.49 ; $\mathrm{I}^{2}=99 \% ; \mathrm{P}=0.02$ ) whilst hospital stay length was comparable between the cohorts (WMD -1.58 ; 95\% CI: -4.41 to 


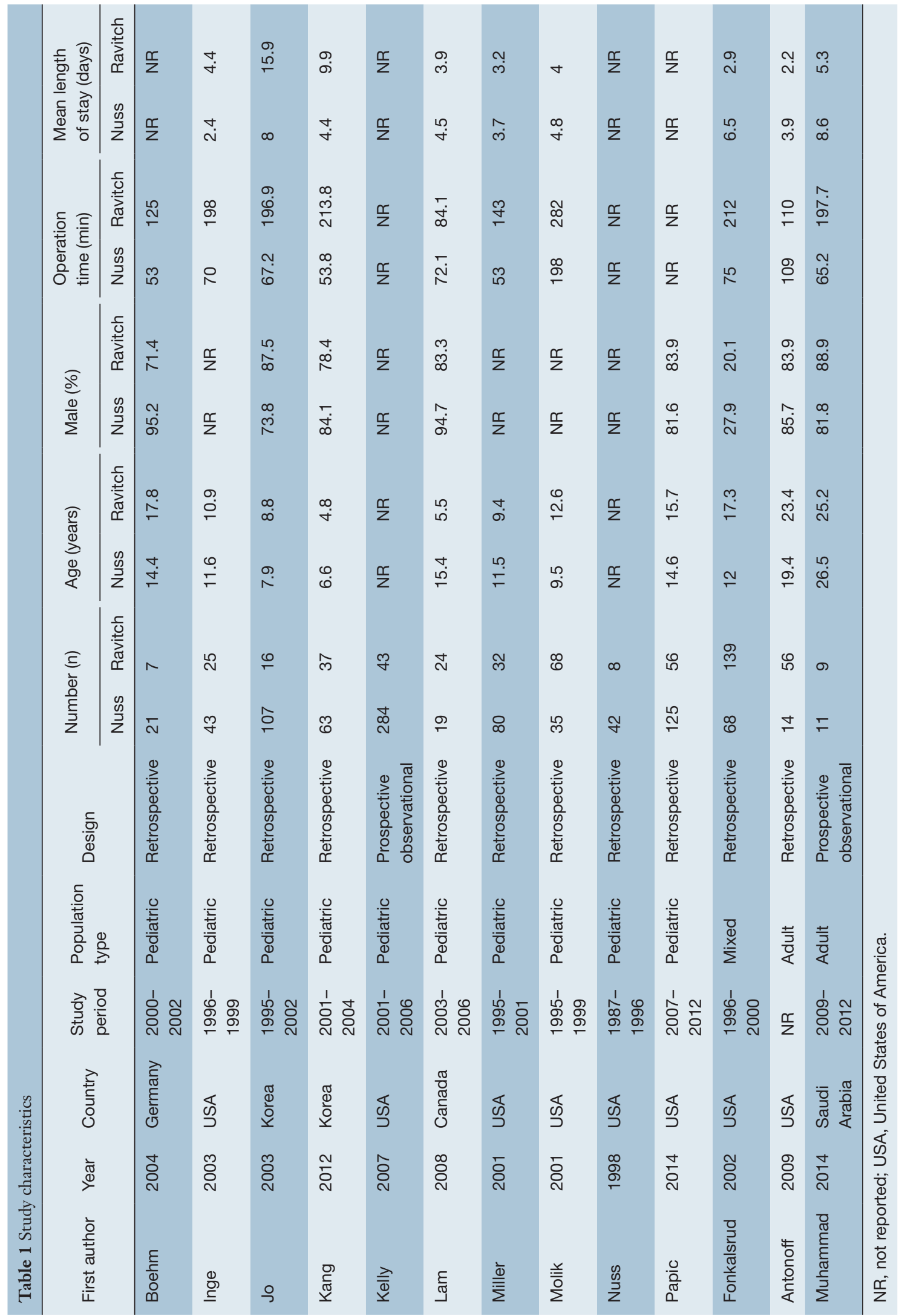




\begin{tabular}{|c|c|c|c|c|c|}
\hline Number of patients & 520 & 912 & - & - & - \\
\hline Pneumothorax (\%) & 2.1 & 4.2 & 1.89 & $0.91-3.93$ & 0.09 \\
\hline Hemothorax (\%) & 0.8 & 1.4 & 0.74 & $0.21-2.65$ & 0.64 \\
\hline Pneumonia (\%) & 0.7 & 0.1 & 0.27 & $0.04-1.67$ & 0.16 \\
\hline Reoperation (\%) & 3.3 & 7.7 & 3.02 & $0.84-10.89$ & 0.09 \\
\hline Early complications (\%) & 13.5 & 26.4 & 1.46 & $0.76-2.78$ & 0.26 \\
\hline Pediatric complications (\%) & 18.6 & 28.3 & 1.16 & $0.61-2.19$ & 0.65 \\
\hline
\end{tabular}

1.26; $\left.\mathrm{I}^{2}=99 \% ; \mathrm{P}=0.28\right)$. Other operative parameters such as analgesia duration and mean blood loss were not well reported and thus could not be pooled.

\section{Overall, early, and late complications}

Across all pooled studies regardless of population type, there was no significant difference in overall complications found between the Nuss group versus Ravitch group $(\mathrm{OR}=1.58$; 95\% CI: 0.86-2.90; I ${ }^{2}=62 \% ; \mathrm{P}=0.14$ ) (Table 2, Figure 2). When considering only the pediatric subgroup, comparable overall complication rates were found between the two groups ( $\mathrm{OR}=1.16 ; 95 \%$ CI: 0.61-2.19; $\left.\mathrm{I}^{2}=56 \% ; \mathrm{P}=0.65\right)$. However, there lower overall complication rates for the Ravitch cohort when considering the mixed populations subgroup $(\mathrm{OR}=7.98$; 95\% CI: $3.00-21.25 ; \mathrm{P} \leq 0.0001)$ and adult population subgroup ( $\mathrm{OR}=3.26 ; 95 \%$ CI: $1.01-10.46 ; \mathrm{I}^{2}=0 \% ; \mathrm{P}=0.05$ ).

Early complications (occurring within 1 month of the procedure) were reported in 10 studies focusing on pediatric patients undergoing surgery for pectus excavatum. No differences in early complication rates were found between Nuss versus Ravitch surgery ( $\mathrm{OR}=1.02,95 \%$ CI: $0.51-2.03$; $\left.\mathrm{I}^{2}=59 \% ; \mathrm{P}=0.95\right)$. In the one study with mixed population, lower early complications were found in the Ravitch group $(\mathrm{P}<0.0001)$. Similarly, in adult cases, significantly lower early complication rate was found in the Ravitch group (13.8\% vs. $32 \%, \mathrm{OR}=3.26 ; 95 \%$ CI: $1.01-10.46 ; \mathrm{I}^{2}=0 \% ; \mathrm{P}=0.05$ ).

Late complications were only reported for pediatric studies, and follow-up periods varied considerably. The longest group had 3.5 years of follow-up (9) but most studies reported complications for 1-2 years. No significant difference was found between the two groups ( $4 \%$ vs. $0 \%$; $\mathrm{OR}=3.03 ; 95 \%$ CI: $0.55-16.84 ; \mathrm{I}^{2}=0 \% ; \mathrm{P}=0.21$ ).

\section{Bar displacement}

Bar displacement was reported in 10 comparative studies focusing on pediatric cases of pectus excavatum (Figure 3). A significantly lower rate of bar displacement was found for patients undergoing the Ravitch procedure $(\mathrm{OR}=4.17$; 95\% CI: $\left.1.46-11.96 ; \mathrm{I}^{2}=0 \% ; \mathrm{P}=0.008\right)$. The subgroup with mixed adult and pediatric cases, similarly demonstrated a significantly lower rate of bar displacements for patients undergoing the Ravitch procedure $(\mathrm{P}=0.02)$. Two adult studies reported bar displacement, which was found to be significantly lower for the Ravitch group (OR $=7.07$; 95\% CI: $1.37-36.52 ; \mathrm{P}=0.02)$. Overall across all pooled patients, the Ravitch procedure was found to be associated with a lower rate of bar displacement compared to the minimally invasive Nuss procedure.

\section{Reoperations}

In the pediatric group, reoperation rates were similar between the Nuss and Ravitch procedures (6.1\% vs. 6.4\%; $\mathrm{OR}=1.00 ; 95 \%$ CI: $\left.0.40-2.50 ; \mathrm{I}^{2}=0 \% ; \mathrm{P}=1.00\right)$. However, the Ravitch procedure had a lower reoperation rate for the adult subgroup (5.4\% vs. $28.6 \%$; OR $=7.07$; $95 \%$ CI: $1.37-$ 


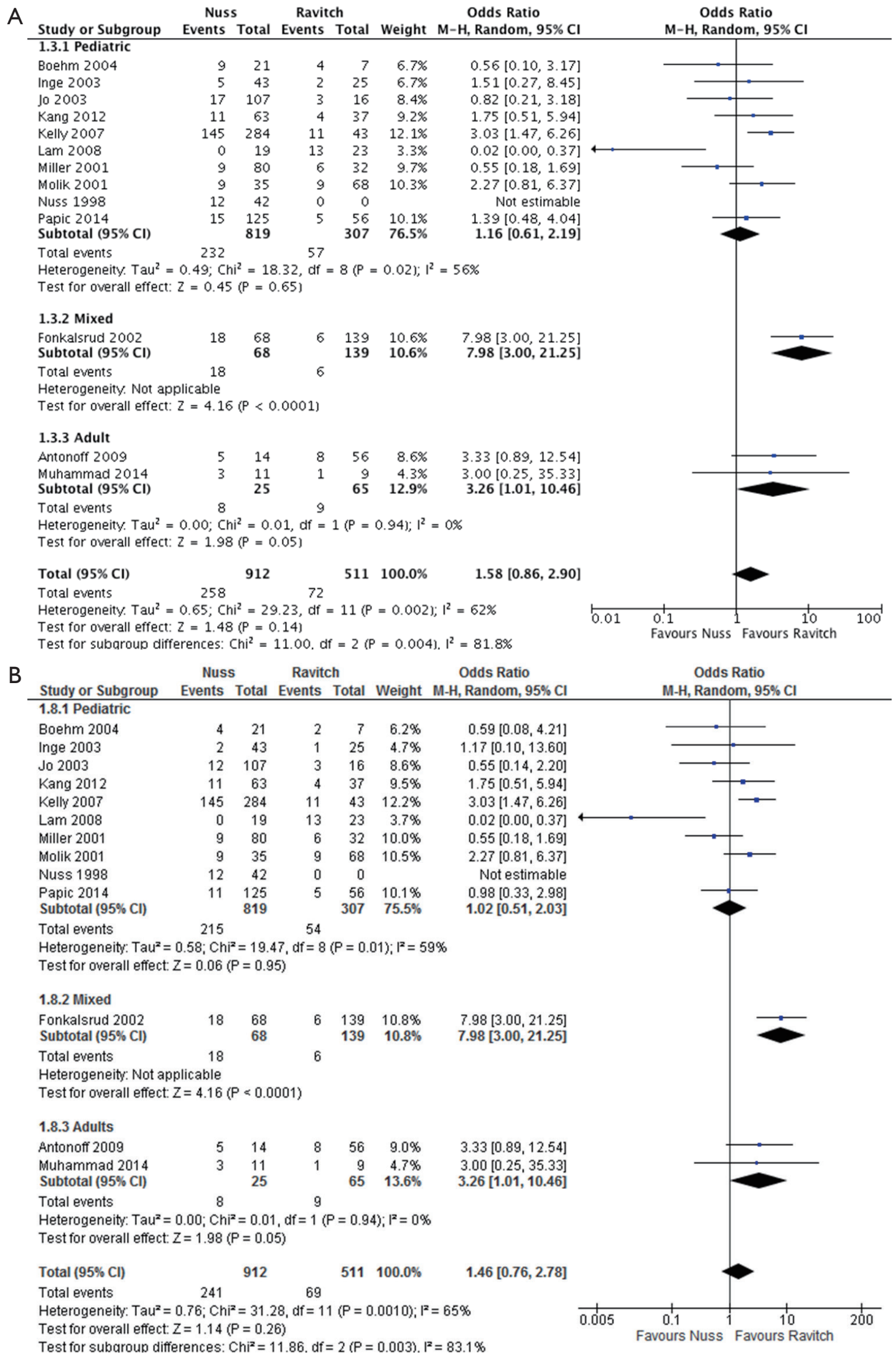




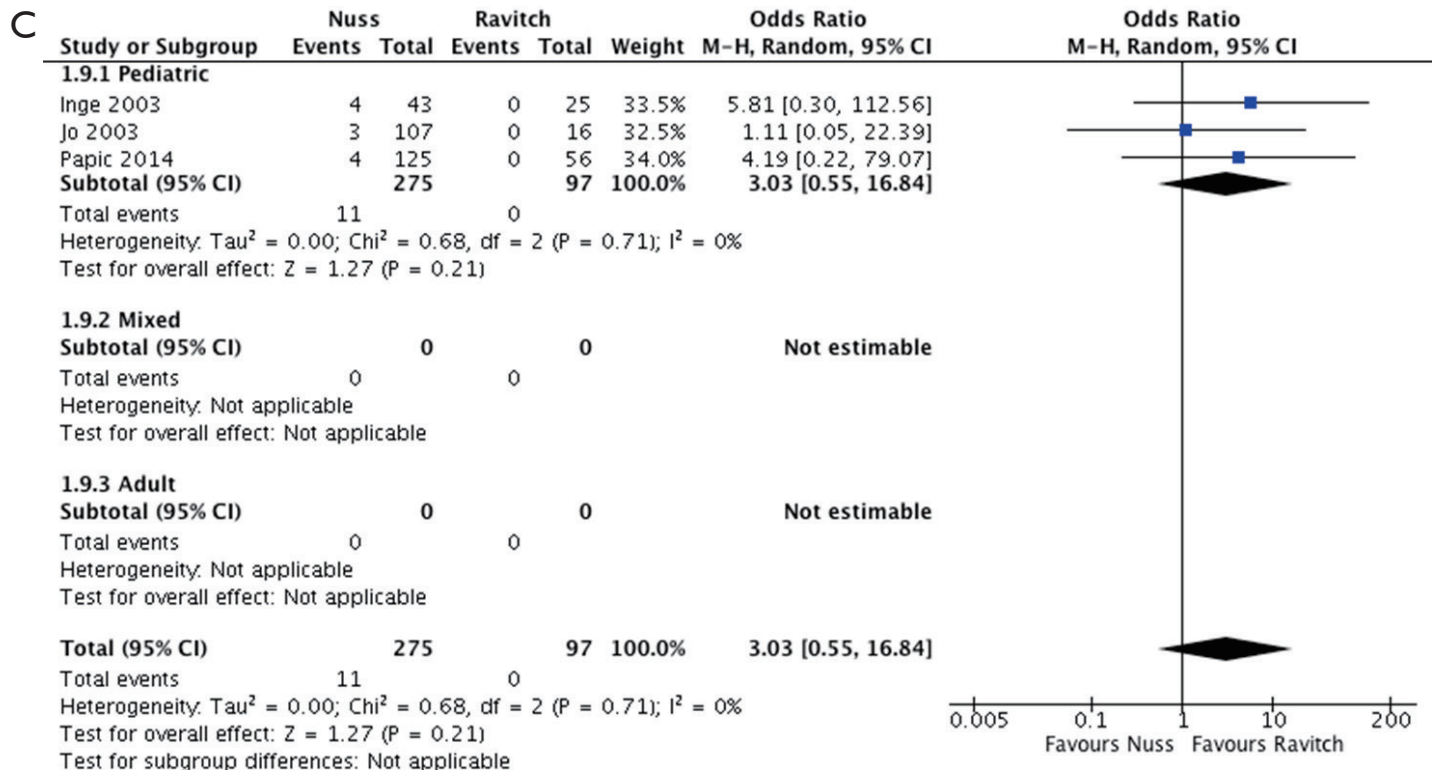

Figure 2 Forest plots of complications in Nuss versus Ravitch surgery for pectus excavatum. (A) Forest plot of overall complications; (B) forest plot of early complications; (C) Forest plot of late complications.

\begin{tabular}{|c|c|c|c|c|c|c|c|c|c|}
\hline \multirow{2}{*}{$\begin{array}{l}\text { Study or Subgroup } \\
1.1 .1 \text { Pediatric }\end{array}$} & \multicolumn{2}{|c|}{ Nuss } & \multicolumn{2}{|c|}{ Ravitch } & \multirow[t]{2}{*}{ Weight } & \multirow{2}{*}{$\begin{array}{l}\text { Odds Ratio } \\
\text { M-H, Random, } 95 \% \mathrm{Cl}\end{array}$} & \multicolumn{3}{|c|}{$\begin{array}{l}\text { Odds Ratio } \\
\mathrm{M}-\mathrm{H} \text {, Random, } 95 \% \mathrm{Cl}\end{array}$} \\
\hline & & & & & & & & & \\
\hline Boehm 2004 & 2 & 21 & 0 & 7 & $7.2 \%$ & $1.92[0.08,44.92]$ & & & \\
\hline Inge 2003 & 4 & 43 & 0 & 25 & $8.2 \%$ & $5.81[0.30,112.56]$ & & & \\
\hline Jo 2003 & 3 & 107 & 0 & 16 & $7.9 \%$ & $1.11[0.05,22.39]$ & & & \\
\hline Kang 2012 & 0 & 0 & 0 & 0 & & Not estimable & & & \\
\hline Kelly 2007 & 7 & 284 & 0 & 43 & $8.7 \%$ & $2.35[0.13,41.91]$ & & & \\
\hline Lam 2008 & 0 & 0 & 0 & 0 & & Not estimable & & & \\
\hline Miller 2001 & 4 & 80 & 0 & 32 & $8.3 \%$ & $3.82[0.20,73.08]$ & & & \\
\hline Molik 2001 & 4 & 35 & 0 & 68 & $8.2 \%$ & $19.57[1.02,374.70]$ & & & \\
\hline Nuss 1998 & 2 & 42 & 0 & 42 & $7.6 \%$ & $5.25[0.24,112.66]$ & & & \\
\hline $\begin{array}{l}\text { Papic } 2014 \\
\text { Subtotal }(95 \% \mathrm{CI})\end{array}$ & 7 & $\begin{array}{l}125 \\
737\end{array}$ & 0 & $\begin{array}{r}56 \\
289\end{array}$ & $\begin{array}{r}8.7 \% \\
64.8 \%\end{array}$ & $\begin{array}{l}7.15[0.40,127.43] \\
4.17[1.46,11.96]\end{array}$ & & & \\
\hline \multicolumn{10}{|c|}{$\begin{array}{l}\text { Heterogeneity. } \mathrm{Tau}^{2}=0.00 ; \mathrm{Chi}^{2}=2.43, \mathrm{df}=7(\mathrm{P}=0.93) ; \mathrm{I}^{2}=0 \% \\
\text { Test for overall effect: } \mathrm{Z}=2.66(\mathrm{P}=0.008)\end{array}$} \\
\hline \multicolumn{10}{|l|}{ 1.1.2 Mixed } \\
\hline $\begin{array}{l}\text { Fonkalsrud } 2002 \\
\text { Subtotal }(95 \% \mathrm{CI})\end{array}$ & 6 & $\begin{array}{l}68 \\
68\end{array}$ & 0 & $\begin{array}{l}139 \\
139\end{array}$ & $\begin{array}{l}8.6 \% \\
8.6 \%\end{array}$ & $\begin{array}{r}29.02[1.61,523.07] \\
29.02[1.61,523.07]\end{array}$ & & & \\
\hline \multicolumn{10}{|c|}{$\begin{array}{l}\text { Heterogeneity. Not applicable } \\
\text { Test for overall effect: } Z=2.28(P=0.02)\end{array}$} \\
\hline \multicolumn{10}{|l|}{ 1.1.3 Adult } \\
\hline Antonoff 2009 & 4 & 14 & 3 & 56 & $26.6 \%$ & $7.07[1.37,36.52]$ & & & \\
\hline $\begin{array}{l}\text { Muhammad } 2014 \\
\text { Subtotal }(95 \% \mathrm{CI})\end{array}$ & 0 & 25 & 0 & 65 & $26.6 \%$ & $\begin{array}{l}\text { Not estimable } \\
7.07[1.37,36.52]\end{array}$ & & & \\
\hline \multicolumn{10}{|c|}{$\begin{array}{l}\text { Heterogeneity. Not applicable } \\
\text { Test for overall effect: } Z=2.33(P=0.02)\end{array}$} \\
\hline Total $(95 \% \mathrm{Cl})$ & & 830 & & 493 & $100.0 \%$ & $5.67[2.43,13.24]$ & & & \\
\hline Total events & 43 & & 3 & & & & & & \\
\hline $\begin{array}{l}\text { Heterogeneity. Tau } \\
\text { Test for overall effect } \\
\text { Test for subaroup dif }\end{array}$ & $\begin{array}{l}0.00 ; \mathrm{Ch} \\
\mathrm{Z}=4.01 \\
\text { erences: }\end{array}$ & $\begin{array}{l}\mathrm{i}^{2}=4 \\
(\mathrm{P}< \\
\mathrm{Chi}^{2}=\end{array}$ & $\begin{array}{l}05, \mathrm{df}= \\
.0001 \mathrm{j} \\
1.62 . \mathrm{df}\end{array}$ & $\begin{array}{l}9(\mathrm{P}= \\
=2(\mathrm{P}=\end{array}$ & $\begin{array}{l}0.91 \mathrm{~J} ; \mathrm{I}^{2}= \\
=0.45 \mathrm{I} .1\end{array}$ & $\begin{array}{l}=0 \% \\
\left.\right|^{2}=0 \%\end{array}$ & 0.002 & $\begin{array}{c}0.1 \\
\text { Favours Nuss }\end{array}$ & 10 \\
\hline
\end{tabular}

Figure 3 Forest plot of bar displacement. 


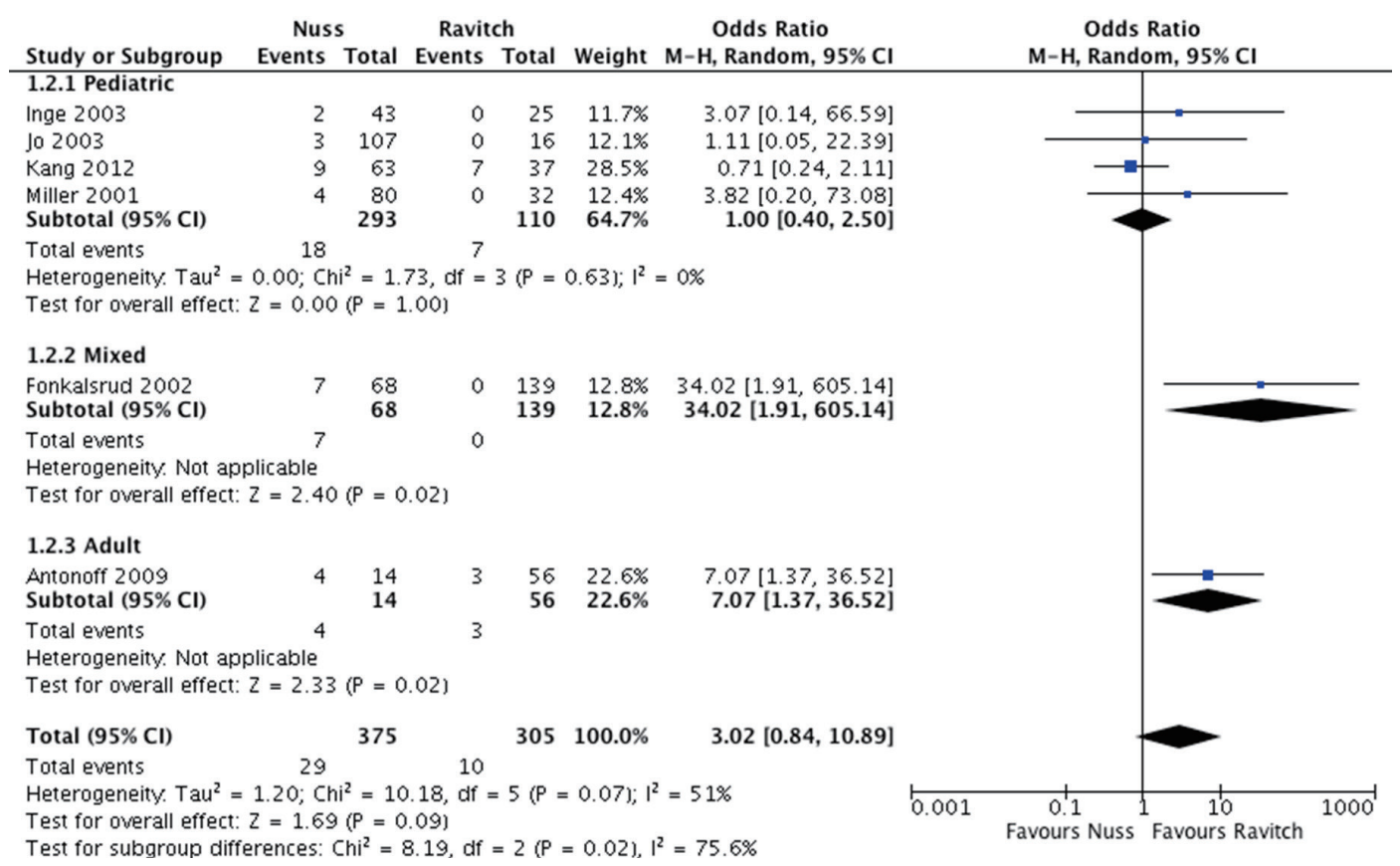

Figure 4 Forest plot of reoperations.

36.52; $\mathrm{P}=0.02)$ (Figure 4).

\section{Wound infection}

Wound infection rates were reported in the pediatric population and were found to be similar between the Nuss and Ravitch procedures (OR $=0.58$; 95\% CI: $0.23-1.46$; $\left.\mathrm{I}^{2}=0 \% ; \mathrm{P}=0.25\right)$. No cases of wound infections were reported in the adult population subgroup (Figure 5).

\section{Hemothorax}

Hemothorax rates were found to be comparable between Nuss and Ravitch procedures for pediatric patients (1.6\% vs. $1.3 \%$; $\mathrm{OR}=0.74 ; 95 \%$ CI: $\left.0.21-2.65 ; \mathrm{I}^{2}=12 \% ; \mathrm{P}=0.64\right)$ (Figure 6).

\section{Pneumothorax}

For the pediatric subgroup, comparable pneumothorax rates were found between the Nuss and Ravitch subgroups (3.4\% vs. $1.5 \%$; OR $=1.11 ; 95 \%$ CI: $\left.0.42-2.93 ; \mathrm{I}^{2}=0 \% ; \mathrm{P}=0.83\right)$. No significant differences were found between the procedures in the adult subgroup; however, there was a trend toward higher incidence in the Nuss group (12\% vs. $4.6 \%$; OR
$=2.15 ; 95 \%$ CI: $0.33-14.17 ; \mathrm{I}^{2}=0 \% ; \mathrm{P}=0.42$ ) (Figure 7).

\section{Pneumonia}

Pneumonia rates were found to be similar between Nuss and Ravitch procedures across pediatric $(\mathrm{OR}=0.15 ; 95 \%$ CI: $\left.0.02-1.48 ; \mathrm{I}^{2}=0 \% ; \mathrm{P}=0.10\right)$ and adult cases $(\mathrm{OR}=0.75$; 95\% CI: 0.03-16.54; $\mathrm{I}^{2}=\mathrm{NA} ; \mathrm{P}=0.86$ ) (Figure 8 ).

\section{Discussion}

Both the Nuss and Ravitch techniques for pectus excavatum repair continue to be in use today, yet most data comparing these procedures is limited to a single institution's experience performing just one of the surgical techniques. These studies typically have small numbers of patients and cannot compare between techniques. Johnson and colleagues surveyed this literature in a systematic review, but given the substantial heterogeneity, were unable to perform a meta-analysis and thus could not meaningfully compare the two techniques (22). There are currently no randomized trials comparing these procedures. Therefore, to address limitations in the current evidence, a systematic review and meta-analysis of Nuss and Ravitch techniques was performed. Using either the Ravitch or 


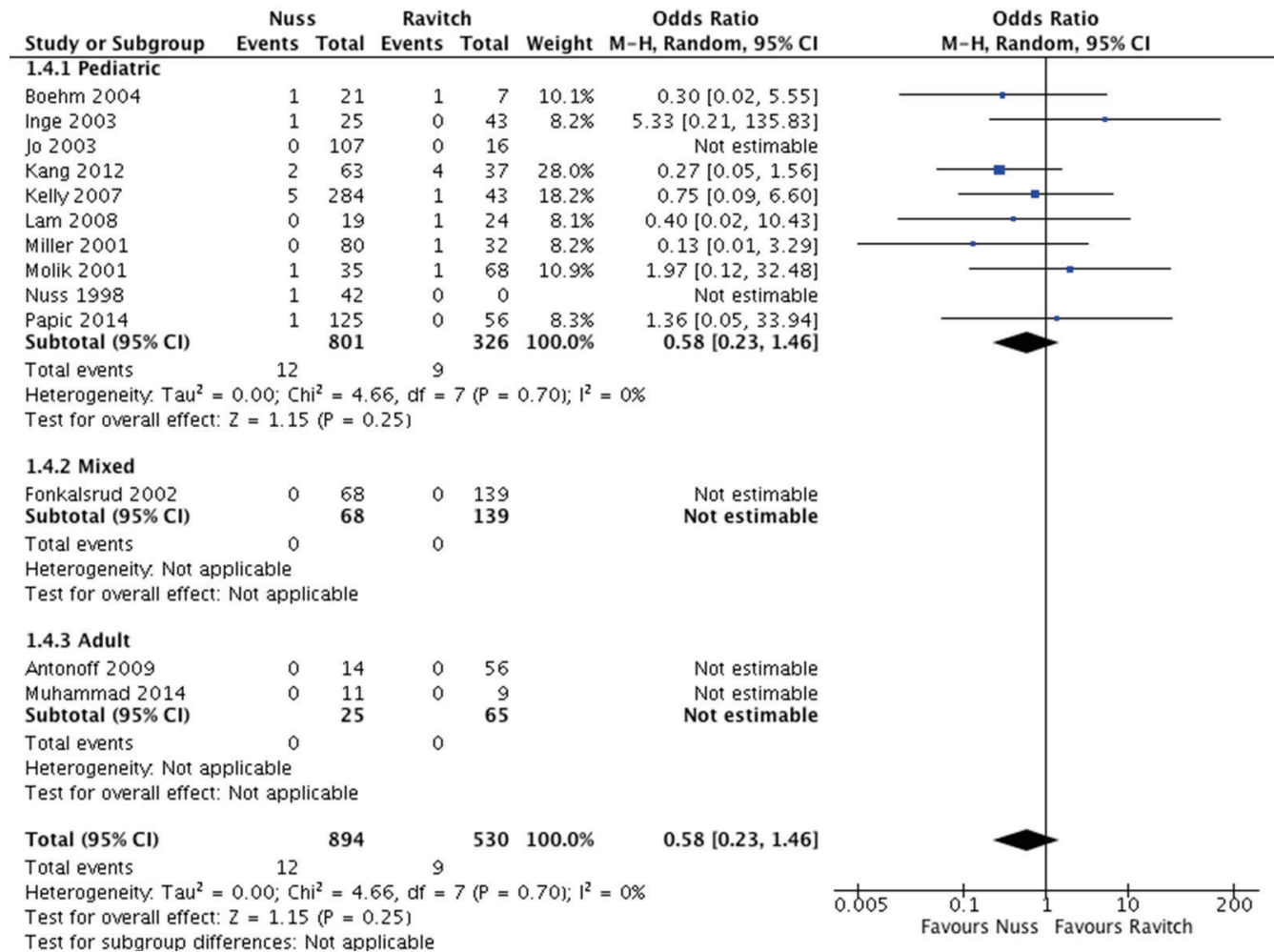

Figure 5 Forest plot of wound infections.

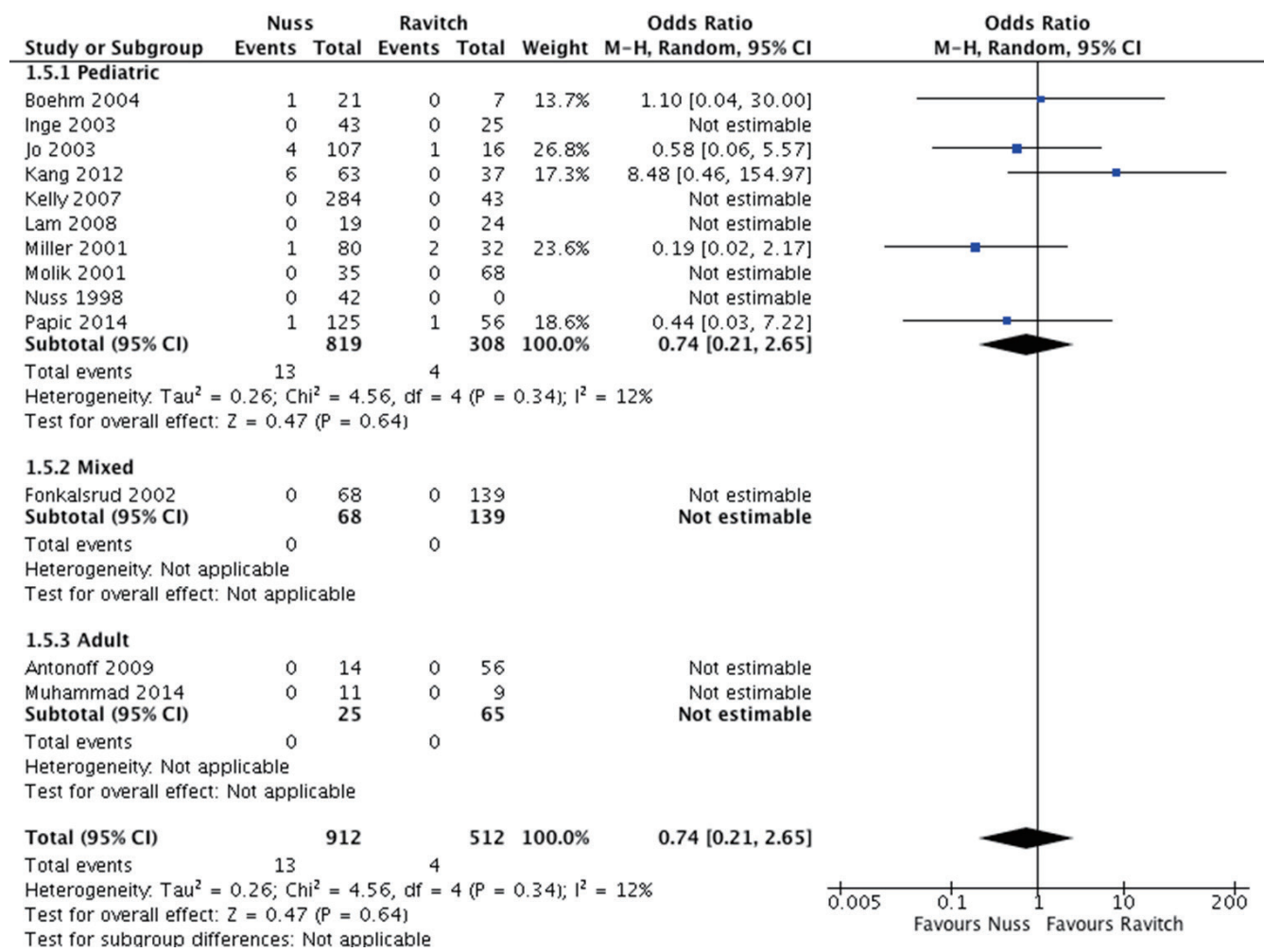

Figure 6 Forest plot of hemothorax. 


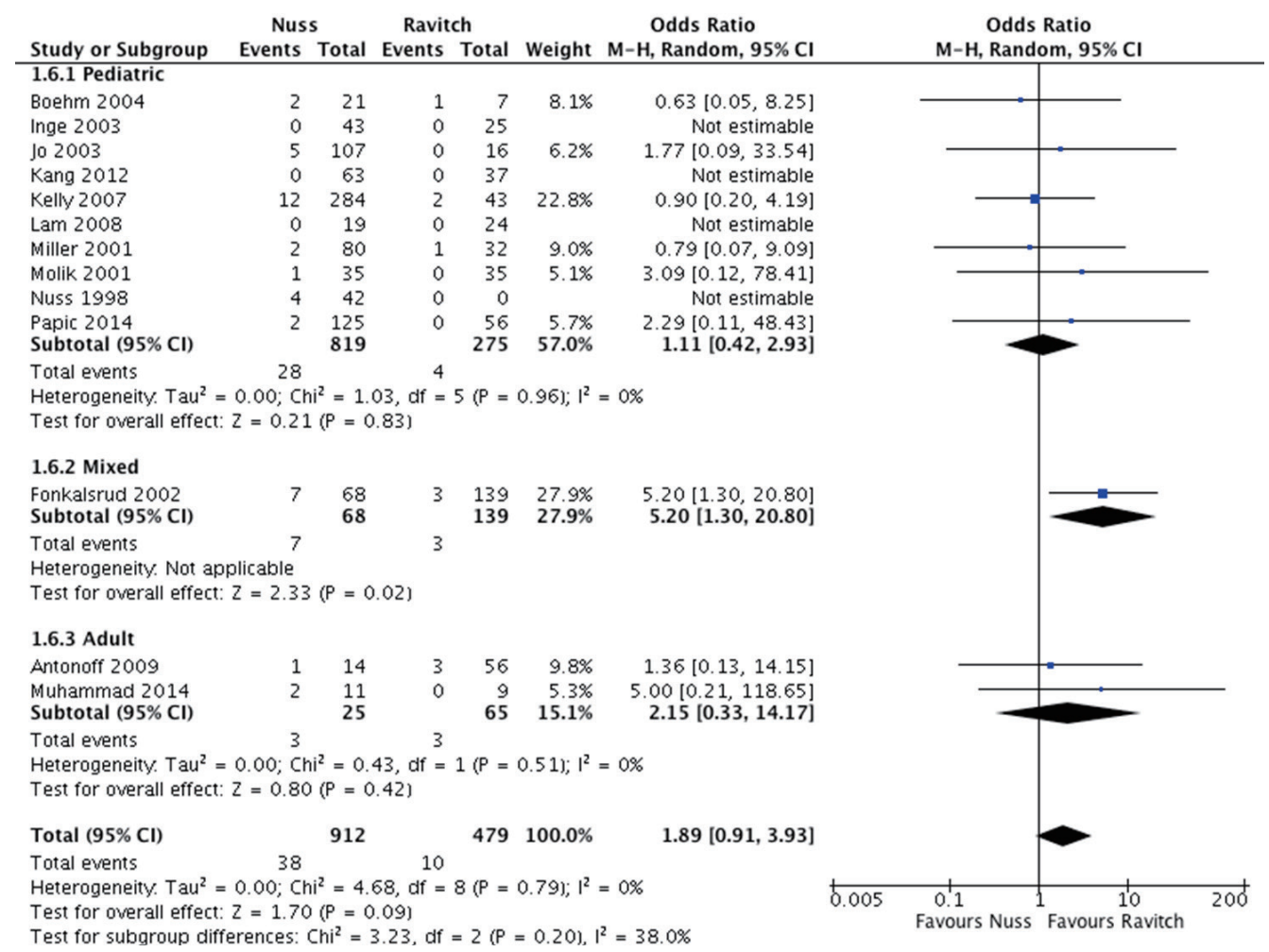

Figure 7 Forest plot of pneumothorax.

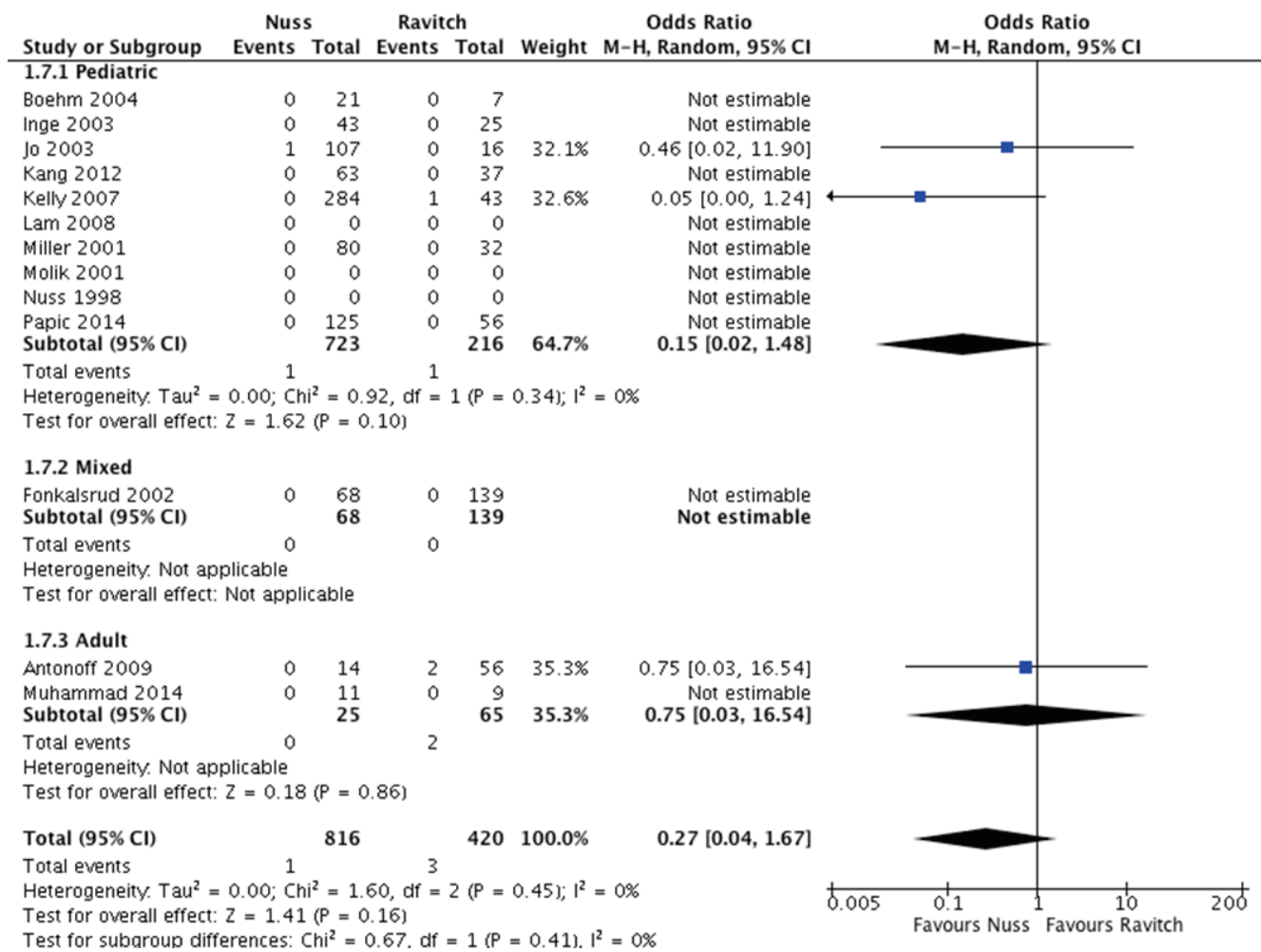

Figure 8 Forest plot of pneumonia. 
Nuss technique results in patients presenting with different sets of complications. However, given that they are both used to repair pectus excavatum, a direct comparison of complications between them is useful, particularly as previous studies have yielded inconsistent results.

Our results suggest that there is no difference in total complication rate between Nuss and Ravitch procedures when considering pediatric populations, for overall, early and late complications. In the adult subgroup, the Ravitch group experienced significantly fewer complications, observed for both overall and early complications. This could be because the additional force required results in longer operations with more complications (23). This subgroup analysis only comprised 90 patients total, reflecting the fact that surgery for pectus excavatum is uncommon in adults. These total complications were almost all early complications, highlighting the necessity of future long-term studies. Long-term data is also needed to determine the impact of each procedure on quality of life and patient satisfaction outcomes for pediatric and adult populations. While both procedures report positive early patient satisfaction, long-term factors such as scarring, which commonly results from using the Ravitch technique, could affect this. There could also be differing levels of patient satisfaction subsequent to bar removal in patients undergoing the Nuss procedure.

For specific complications, there was no difference between the two groups in terms of pneumothorax, hemothorax, wound infection, reoperations or pneumonia. In the adult subgroups, reoperations were significantly higher in Nuss patients compared to Ravitch patients, although this was only reported in two studies. Bar displacement was significantly greater in the Nuss group, as expected, given that only a minority of modified Ravitch procedures used struts, and this proportion was not reported consistently. The Nuss procedure had some clear advantages operationally. It was shorter than the Ravitch procedure and resulted in decreased blood loss, due to the more minimally invasive nature of the Nuss procedure, though this was only reported in a few studies. These results largely agree with the only previous meta-analysis, performed by Nasr and colleagues (7). The main differences were that while they found pneumothorax and reoperation as more frequent in patients undergoing the Nuss procedure, no difference was found in the present meta-analysis. This could be because as the Nuss procedure becomes more widespread, surgical techniques have improved to reduce complications.

Finding data on adult patients was particularly difficult, with just two studies only including adult patients and one other that included pediatric and adult populations (19-21). Previous reports have suggested that complication rates were higher in older patients and while this was not demonstrated in this meta-analysis, it is clear further data is needed (24).

The primary difficulty experienced in conducting this systematic review and meta-analysis was lack of adequate data beyond the end points reported in the original studies. Attempts to investigate preoperative characteristics, such as pulmonary, cardiac and psychiatric comorbidities were only sporadically reported. Other useful measures of operative success, such as time to ambulation and postoperative Haller index were again scarcely recorded. Similarly, despite accounts that the Nuss technique resulted in greater pain, particularly for adult patients, this was unable to be verified due to lack of data either as self-reported data or regarding analgesia duration (25). Even in the complications that are reported here often data were missing in individual studies.

While none of the studies included had a weighting of more than $12.1 \%$ in investigating total complications, about half the total events came from a single study, potentially skewing results (14) and there was substantial statistical heterogeneity. Additionally, the variation in complication rates was large: Nuss procedural complications ranged from less than $10 \%$ to over $50 \%$. This wide range is a result of different operator experience and different reporting of complications and length of follow-up.

Many of these studies reported an institution's experience with adopting the Nuss technique for the first time, while continuing to also perform pectus excavatum repairs with the Ravitch technique. It is likely this led to inflated complications in the Nuss group. For example, Miller and colleagues reported two-thirds of all complications from the Nuss procedure occurring during the first 9 months of experience with this new technique, out of a 6-year study period (16). Fonkalsrud and colleagues also suggested that in the initial stages of adopting the Nuss procedure it resulted in greater morbidity (19). The surgeons included in this systematic review were more likely to have greater experience using the Ravitch technique, at least initially, presenting a potential source of bias.

There is also still heterogeneity in procedural technique, even within groups. Modifications to the Ravitch technique are often made, and these can differ between institutions, leading to inconsistent results and complications (26). In the Nuss procedure, choices about single- or doublelumen ventilation, thoracoscopy, or use of bar stabilizers 
are similarly modifications to the procedure that could affect patient outcomes (27). The challenges in dealing with this are significant, as operating techniques are often not reported, and data is scarce even with combining all Nuss or Ravitch procedures. Patient selection can also contribute to bias, such as severely asymmetrical pectus excavatum patients, among whom the Ravitch technique is often preferred.

In conclusion, the analysis presented here could not definitively suggest a preference for either surgical method of pectus excavatum repair. Complication rates were similar, except in adults where the Nuss technique had more complications. The Nuss technique had some advantages, namely lower blood loss and shorter operative time. The lack of definitive findings is largely due to methodological issues with the data analyzed, which was largely of suboptimal quality. More adult and long-term studies need to be conducted, as there are few studies that directly address this. While more standardized reporting of data. For example, recording patient characteristics such as cardiac, pulmonary and psychiatric comorbidities, operative characteristics such as time to ambulation, fully documenting any complications, using a standardised scale to measure patient satisfaction and recording a post-procedural Haller index. This would increase the quality and quantity of data, but biases would still remain, in variations in operative technique, differing surgeon experience with each technique, and the problems with most data coming from retrospective observational studies. Nevertheless, given that the possibility of a large, randomized trial comparing surgical techniques is remote, these measures are required to ensure that future metaanalyses can make more definitive statements comparing the Nuss and Ravitch techniques.

\section{Acknowledgements}

None.

\section{Footnote}

Conflicts of Interest: The authors have no conflicts of interest to declare.

\section{References}

1. Obermeyer RJ, Goretsky MJ. Chest wall deformities in pediatric surgery. Surg Clin North Am 2012;92:669-84, ix.
2. Funk JF, Gross C, Placzek R. Patient satisfaction and clinical results 10 years after modified open thoracoplasty for pectus deformities. Langenbecks Arch Surg 2011;396:1213-20.

3. Malek MH, Fonkalsrud EW, Cooper CB. Ventilatory and cardiovascular responses to exercise in patients with pectus excavatum. Chest 2003;124:870-82.

4. Lawson ML, Mellins RB, Paulson JF, et al. Increasing severity of pectus excavatum is associated with reduced pulmonary function. J Pediatr 2011;159:256-61.

5. Ravitch MM. The Operative Treatment of Pectus Excavatum. Ann Surg 1949;129:429-44.

6. Nuss D, Kelly RE Jr, Croitoru DP, et al. A 10-year review of a minimally invasive technique for the correction of pectus excavatum. J Pediatr Surg 1998;33:545-52.

7. Nasr A, Fecteau A, Wales PW. Comparison of the Nuss and the Ravitch procedure for pectus excavatum repair: a meta-analysis. J Pediatr Surg 2010;45:880-6.

8. Moher D, Liberati A, Tetzlaff J, et al. Preferred reporting items for systematic reviews and meta-analyses: the PRISMA statement. PLoS Med 2009;6:e1000097.

9. Phan K, Tian DH, Cao C, et al. Systematic review and meta-analysis: techniques and a guide for the academic surgeon. Ann Cardiothorac Surg 2015;4:112-22.

10. Boehm RA, Muensterer OJ, Till H. Comparing minimally invasive funnel chest repair versus the conventional technique: an outcome analysis in children. Plast Reconstr Surg 2004;114:668-73; discussion 674-5.

11. Inge TH, Owings E, Blewett CJ, et al. Reduced hospitalization cost for patients with pectus excavatum treated using minimally invasive surgery. Surg Endosc 2003;17:1609-13.

12. Jo WM, Choi YH, Sohn YS, et al. Surgical treatment for pectus excavatum. J Korean Med Sci 2003;18:360-4.

13. Kang CH, Park S, Park IK, et al. Long-term Surveillance Comparing Satisfaction between the Early Experience of Nuss Procedure vs. Ravitch Procedure. Korean J Thorac Cardiovasc Surg 2012;45:308-15.

14. Kelly RE Jr, Shamberger RC, Mellins RB, et al. Prospective multicenter study of surgical correction of pectus excavatum: design, perioperative complications, pain, and baseline pulmonary function facilitated by internet-based data collection. J Am Coll Surg 2007;205:205-16.

15. Lam MW, Klassen AF, Montgomery CJ, et al. Quality-oflife outcomes after surgical correction of pectus excavatum: a comparison of the Ravitch and Nuss procedures. J Pediatr Surg 2008;43:819-25. 
16. Miller KA, Woods RK, Sharp RJ, et al. Minimally invasive repair of pectus excavatum: a single institution's experience. Surgery 2001;130:652-7; discussion 657-9.

17. Molik KA, Engum SA, Rescorla FJ, et al. Pectus excavatum repair: experience with standard and minimal invasive techniques. J Pediatr Surg 2001;36:324-8.

18. Papic JC, Finnell SM, Howenstein AM, et al. Postoperative opioid analgesic use after Nuss versus Ravitch pectus excavatum repair. J Pediatr Surg 2014;49:919-23; discussion 923.

19. Fonkalsrud EW, Beanes S, Hebra A, et al. Comparison of minimally invasive and modified Ravitch pectus excavatum repair. J Pediatr Surg 2002;37:413-7.

20. Antonoff MB, Erickson AE, Hess DJ, et al. When patients choose: comparison of Nuss, Ravitch, and Leonard procedures for primary repair of pectus excavatum. J Pediatr Surg 2009;44:1113-8; discussion 118-9.

21. Muhammad MI. Thoracoscopic repair of pectus excavatum using different bar stabilizers versus open repair. Asian

Cite this article as: Kanagaratnam A, Phan S, Tchantchaleishvilli V, Phan K. Ravitch versus Nuss procedure for pectus excavatum: systematic review and meta-analysis. Ann Cardiothorac Surg 2016;5(5):409-421. doi: 10.21037/acs.2016.08.06
Cardiovasc Thorac Ann 2014;22:187-92.

22. Johnson WR, Fedor D, Singhal S. Systematic review of surgical treatment techniques for adult and pediatric patients with pectus excavatum. J Cardiothorac Surg 2014;9:25.

23. Kim DH, Hwang JJ, Lee MK, et al. Analysis of the Nuss procedure for pectus excavatum in different age groups. Ann Thorac Surg 2005;80:1073-7.

24. Fonkalsrud EW. Current management of pectus excavatum. World J Surg 2003;27:502-8.

25. Hebra A, Swoveland B, Egbert M, et al. Outcome analysis of minimally invasive repair of pectus excavatum: review of 251 cases. J Pediatr Surg 2000;35:252-7; discussion 257-8.

26. Fonkalsrud EW. Open repair of pectus excavatum with minimal cartilage resection. Ann Surg 2004;240:231-5.

27. Protopapas AD, Athanasiou T. Peri-operative data on the Nuss procedure in children with pectus excavatum: independent survey of the first 20 years' data. J Cardiothorac Surg 2008;3:40. 